\title{
A clinically feasible multiplex proteomic immunoassay as a novel functional diagnostic for pancreatic ductal adenocarcinoma
}

\author{
Kian-Huat Lim ${ }^{1}$, Emma Langley5 ${ }^{5}$ Feng $\mathrm{Gao}^{4}$, Jingqin Luo ${ }^{4}$, Lin Li ${ }^{1}$, Gary Meyer ${ }^{5}$, \\ Phillip Kim ${ }^{5}$, Sharat Singh ${ }^{5}$, Vladamir M. Kushnir ${ }^{2}$, Dayna S. Early ${ }^{2}$, Daniel K. \\ Mullady ${ }^{2}$, Steven A. Edmundowicz ${ }^{6}$, Sachin Wani ${ }^{6}$, Faris M. Murad7, Dengfeng Cao ${ }^{3}$, \\ Riad R. Azar ${ }^{2}$ and Andrea Wang-Gillam ${ }^{1}$ \\ ${ }^{1}$ Division of Oncology, Department of Internal Medicine, Washington University School of Medicine, St. Louis, MO, USA \\ 2 Division of Gastroenterology, Department of Internal Medicine, Washington University School of Medicine, St. Louis, MO, \\ USA \\ ${ }^{3}$ Department of Pathology and Immunology, Washington University School of Medicine, St. Louis, MO, USA \\ ${ }^{4}$ Department of Surgery, Division of Public Health Sciences, Washington University School of Medicine, St. Louis, MO, USA \\ ${ }^{5}$ Prometheus Laboratories Inc., San Diego, CA, USA \\ ${ }^{6}$ Division of Gastroenterology and Hepatology, University of Colorado Anschutz Medical Campus, Aurora, CO, USA \\ ${ }^{7}$ NorthShore University HealthSystem, Evanston, IL, USA
}

Correspondence to: Andrea Wang-Gillam, email: awang@dom.wustl.edu

Keywords: pancreatic cancer, proteomics, fine-needle aspiration, signaling events, prognosis

Received: January 28, $2017 \quad$ Accepted: February 16, $2017 \quad$ Published: February 23, 2017

Copyright: Lim et al. This is an open-access article distributed under the terms of the Creative Commons Attribution License (CC-BY), which permits unrestricted use, distribution, and reproduction in any medium, provided the original author and source are credited.

\section{ABSTRACT}

To date, targeted therapy for pancreatic ductal adenocarcinoma (PDAC) remains largely unsuccessful in the clinic. Current genomics-based technologies are unable to reflect the quantitative, dynamic signaling changes in the tumor, and require larger tumor samples that are difficult to obtain in PDAC patients. Therefore, a highly sensitive functional tool that can reliably and comprehensively inform intratumoral signaling events is direly needed to guide treatment decision. We tested the utility of a highly sensitive proteomics-based functional diagnostic platform, Collaborative Enzyme Enhanced Reactive-immunoassay (CEER ${ }^{\mathrm{TM}}$ ), on fine-needle aspiration (FNA) samples obtained from 102 patients with radiographically-evident pancreatic tumors. Two FNA passes were collected from each patient, hybridized to customized chips coated with an array of capture antibodies, and detected using two enzyme-conjugated antibodies which emit quantifiable signals. We demonstrate that this technique is highly sensitive in detecting total and phosphorylated forms of multiple signaling molecules in FNA specimens, with reasonable correlation of marker intensities between two different FNA passes. Notably, signals of several markers were significantly higher in PDAC compared to non-cancerous samples. In PDAC samples, we found high total c-Met signal to be associated with poor survival, and confirmed this finding using an independent PDAC tissue microarray.

\section{INTRODUCTION}

To date, the prognosis for pancreatic ductal adenocarcinoma (PDAC) remains dismal. Complete surgical resection offers the only chance for cure, but is limited to a small fraction of patients who are diagnosed at early stage. Even then, most patients who undergo seemingly successful resection eventually succumb to disease relapse despite adjuvant treatment [1]. Underlying the aggressive nature of PDAC is a complex, deregulated signaling circuitry woven by several genetic alterations such as oncogenic mutations of KRas, overexpression of $E G F R / H E R$ family members, and loss of key tumor suppressors including p53, CDKN2A and SMAD4, which cooperatively enhance the survival of PDAC cells and resist the killing effect of therapies [2-5]. Although targeting these deregulated signaling events holds promise to improve the outcome of PDAC patients, 
clinical success remains limited [6]. The advent of next generation sequencing technologies has helped realize the goal of "personalized oncology" by allowing patients to be allocated to clinical trials tailored towards genomic alterations found in their tumors [7]. These techniques, despite being promising, have met with their own set of challenges, which include low tumor cellularity that is typical of PDAC, tumor heterogeneity, clonal evolution, and importantly, frequent discordance between genotype and cancer phenotype [8]. On the other hand, a "functional" diagnostic based on proteomics may serve as a useful complementary tool by providing the most direct link to the phenotype of cancer cells [9]. As most targeted agents are signaling modulators, a proteomicsbased diagnostic that can inform the biological effect of targeted agents in real-time within the tumor will be extremely helpful in assessing treatment response, identifying potential resistance mechanisms and guiding further treatment decision, all of which are impossible using archived tumor samples.

In this study, we report the use of a multiplex proteomic-based assay, Collaborative Enzyme Enhanced Reactive-immunoassay $\left(\mathrm{CEER}^{\mathrm{TM}}\right)$, that is clinically feasible, highly sensitive and specific. This platform was previously shown to be successful in detecting rare "HER2-activated" circulating tumor cells in HER2-negative metastatic breast cancer patients [10], indicating its high sensitivity and ability to provide potentially actionable information beyond the genomic and transcriptomic levels. We show that the CEER ${ }^{\mathrm{TM}}$ platform allows simultaneous detection of the abundance and activation status of multiple key signaling molecules (or "markers") that are uniquely deregulated in PDAC but not in normal tissues obtained from fine-needle aspirations (FNA), indicating high specificity and sensitivity. Encouragingly, while correlating the intensity of each marker to prognosis we found high c-MET signal in FNA specimens to be associated with poor prognosis, which is consistent with published literature based on immunohistochemistry of resected specimens, indicating great potential of this platform in studies of advanced, inoperable PDAC tumors in the future. Finally, we identified markers with previously unreported prognostic significance that may unveil novel understanding to PDAC biology.

\section{RESULTS}

\section{Patient characteristics}

Between year 2010-2012, 102 patients with radiographic suspicion of pancreatic tumor underwent endoscopic ultrasonography (EUS) and fine-needle aspiration (FNA) of the primary pancreatic mass at
Washington University School of Medicine and the affiliated Siteman Cancer Center (Figure 1A). Besides obtaining specimens needed to establish a histologic diagnosis, two additional FNA passes from the same tumor were collected for $\mathrm{CEER}^{\mathrm{TM}}$ analysis. A cytological diagnosis of adenocarcinoma was initially made in 75 patients. However, one patient was later diagnosed with lung adenocarcinoma with pancreatic metastasis and another had extrahepatic cholangiocarcinoma with invasion to the pancreatic head. We excluded three other patients with PDAC who were lost to follow up from our institution. On the other hand, 13 patients had negative cytology, i.e. no evidence of malignant cells were detected from the initial cytological analysis. Three of these patients were later excluded after repeat biopsy showed malignancies including lymphoma, cholangiocarcinoma and pancreatic adenocarcinoma. Finally, five FNA samples showed neuroendocrine tumor and another nine were indeterminate due to insufficient tissue material. In summary, we focused our analyses on the 70 confirmed PDAC specimens with complete clinical follow up, and 10 specimens with negative (or non-cancerous) cytology (Figure 1A). These cytopathologic diagnoses of these ten negative samples were: 2 normal lymphoid content, 1 cystic content with bland epithelium, 5 benign pancreatic elements with reactive inflammatory elements, 2 nondiagnostic with scant cellularity.

Characteristics of all 102 patients and the 70 PDAC patients are provided in Table 1 . For CEER ${ }^{\mathrm{TM}}$ analysis, all FNA samples were collected and immediately processed to maximally preserve the phosphorylation status of each marker (Figure 1B). A total of 18 markers were assayed in the CEER ${ }^{\mathrm{TM}}$ platform (see Material and Methods section and Table 2). All 70 patients were treated at Washington University School of Medicine and followed for up to five years or until death.

\section{Comparison of different FNA passes and between negative and positive PDAC samples}

We first compared whether the signal intensities of each marker varied between the two FNA passes from each patient. As shown in Table 2, we observed modest to moderate degrees of consistency (Spearman's rho coefficients $0.32 \sim 0.59$ ) in the signal intensity between both passes across all markers. This result is highly reflective of the known low cellularity and potentially high intratumoral heterogeneity of PDAC tumors [3, $11]$, underscoring the need to obtain more than one pass for better representation of the whole tumor. To better represent tumor cell signaling, the FNA pass with higher level of cytokeratin (CK), a specific marker for epithelial cells [12], was used in subsequent analyses.

To determine specificity, we next compared the intensity of each marker between the 70 PDAC and 10 


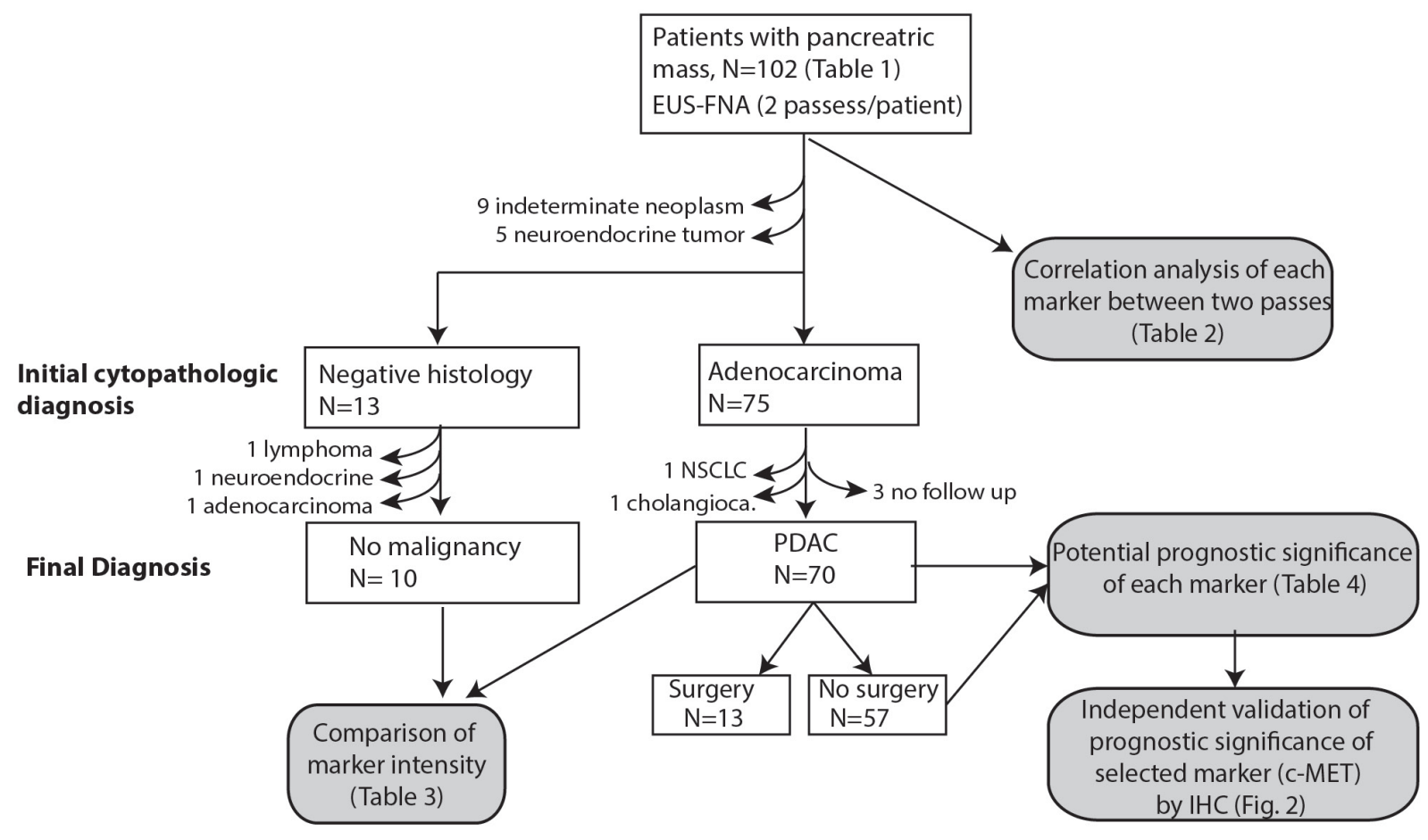

B

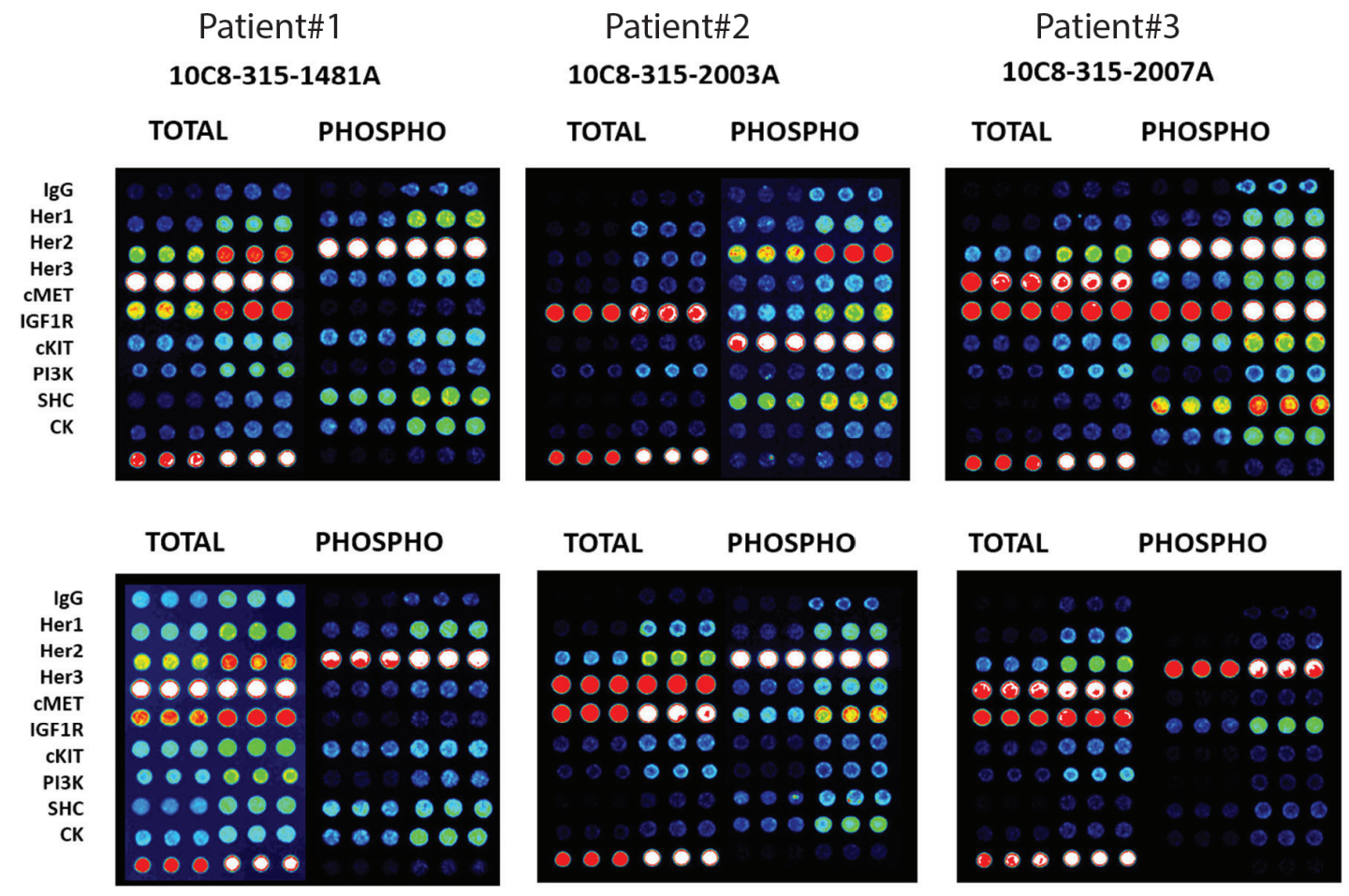

FNA \#1

FNA \#2

Figure 1: A. Flow diagram summarizing workflow of all analyses performed and reasons for inclusion and exclusion of subject for CEER studies. B. Representative images of CEER ${ }^{\mathrm{TM}}$ arrays obtained from two FNA passes (\#1 and \#2) of three patients. Signal intensities ranges from dark (low) to bright white (high). 
Table 1: Characteristics of patients enrolled into studies

\begin{tabular}{|c|c|c|}
\hline Characteristics & All patients $(\mathrm{N}=102)$ & $\begin{array}{l}\text { Confirmed PDAC, evaluable } \\
(\mathrm{N}=70)\end{array}$ \\
\hline $\begin{array}{l}\text { Median Age (range) } \\
\leq 65 \\
>65\end{array}$ & $\begin{array}{l}67.5(38-89) \\
45(44 \%) \\
57(56 \%)\end{array}$ & $\begin{array}{l}69.5(38-89) \\
29(41 \%) \\
41(59 \%)\end{array}$ \\
\hline $\begin{array}{l}\text { Gender (All) } \\
\text { Male } \\
\text { Female }\end{array}$ & $\begin{array}{l}53(52 \%) \\
49(48 \%)\end{array}$ & $\begin{array}{l}34(48.5 \%) \\
36(51.5 \%)\end{array}$ \\
\hline $\begin{array}{l}\text { Race } \\
\text { Caucasian } \\
\text { Non-Caucasian }\end{array}$ & $\begin{array}{l}89(87.2 \%) \\
13(12.8 \%)\end{array}$ & $\begin{array}{l}60(85.7 \%) \\
10(14.3 \%)\end{array}$ \\
\hline $\begin{array}{l}\text { Location of tumor } \\
\text { Head } \\
\text { Non-head }\end{array}$ & $\begin{array}{l}57(55.9 \%) \\
45(44.1 \%)\end{array}$ & $\begin{array}{l}38(54.3 \%) \\
32(45.7 \%)\end{array}$ \\
\hline Tumor size (mm), median (range) & $29(17-70)$ & $29(13-70)$ \\
\hline $\begin{array}{l}\text { Final cytopathologic diagnosis } \\
\text { PDAC } \\
\text { Neuroendocrine } \\
\text { Indeterminate } \\
\text { Negative } \\
\text { Other cancer }\end{array}$ & $\begin{array}{l}74(72.5 \%) \\
6(5.9 \%) \\
9(8.9 \%) \\
10(9.8 \%) \\
3(2.9 \%)\end{array}$ & \\
\hline $\begin{array}{l}\text { Initial Clinical Staging } \\
\text { Resectable } \\
\text { Borderline resectable/locally advanced } \\
\text { Metastatic }\end{array}$ & & $\begin{array}{l}12(17.1 \%) \\
37(52.9 \%) \\
21(30 \%)\end{array}$ \\
\hline $\begin{array}{l}\text { Treatment } \\
\text { Surgery } \\
\text { No surgery (chemo } \pm \text { radiation) }\end{array}$ & & $\begin{array}{l}13(18.5 \%) \\
57(71.5 \%)\end{array}$ \\
\hline
\end{tabular}

negative specimens (Table 3). First, we noted significantly higher CK signals in PDAC samples, compared to negative samples $(p=0.002)$, indicating presence of neoplastic epithelial content in PDAC samples. Remarkably, we also noted significantly higher signal intensities in several markers in PDAC samples. These include p-HER2 ( $p=$ $0.007), \mathrm{p}-\mathrm{HER} 3(p=0.026)$, total HER2 $(p=0.006)$, total HER3 $(p=0.008)$, total c-MET $(p<0.001)$, total IGFR $(p=0.012), \mathrm{p}-\mathrm{AKT}(p=0.046), \mathrm{p}-\mathrm{ERK} 1 / 2(p<0.001)$ and p-PRAS40 $(p=0.043)$. In addition, a trend towards increased p-c-MET $(p=0.051)$ in PDAC was seen. Of these markers, total c-Met and p-ERK1/2 signals showed the strongest statistical difference between PDAC and negative samples (both $p<0.001$ ), resonating previous reports that c-MET and p-ERK1/2 immunohistochemical staining to be markedly elevated in resected PDAC samples compared to normal pancreas [13-15]. In addition, the stronger $\mathrm{p}-\mathrm{ERK} 1 / 2$ signal in PDAC samples is consistent with these kinases being key substrates that are activated downstream of mutant KRas protein, which is present in almost all PDAC $[16,17]$. Overall, these results demonstrate that the $\mathrm{CEER}^{\mathrm{TM}}$ technique is a robust, highly sensitive and specific tool that is capable of detecting salient signaling aberrations from the FNA specimens of PDAC patients.

\section{Prognostic significance of measured markers}

Apart from having different intensities between PDAC and negative samples, we also noted wide patientto-patient variation in intensities of all biomarkers, as discerned by the high standard deviations relative to the mean values of each marker (Table 3). Therefore, we hypothesize that the intensity of each marker, which represents the activity of various signaling pathways, may reflect the biology of the tumor and hence patient prognosis. Particularly, since the prognostic significance of some of these biomarkers, including c-Met, p-AKT and p-ERK1/2 have been published using immunohistochemical analyses of resected tumor samples, which arguably is the "gold standard" technique, we reasoned that being able to recapitulate similar findings using FNA specimens would, to some extent, validate the accuracy of this novel technique and substantiate its utility in future clinical application, particularly for most PDAC patients with inoperable disease where large amount of tumor specimen is not available. To this end, we followed all 70 PDAC patients for up to five years or until death. We divided all 70 PDAC patients into two survival groups ( $\leq$ or $>$ median), using overall median survival (11.5 
Table 2: Spearman correlation coefficients of each marker between two passes

\begin{tabular}{|l|c|c|c|}
\hline \multicolumn{1}{|c|}{ Variables } & N & $\begin{array}{c}\text { Spearman } \\
\text { coefficient }\end{array}$ & P value \\
\hline Total Cytokeratin & 96 & 0.54005 & $<.0001$ \\
Phospho-HER1 & 99 & 0.59002 & $<.0001$ \\
Phospho-HER2 & 97 & 0.50394 & $<.0001$ \\
Phospho-HER3 & 91 & 0.53424 & $<.0001$ \\
Phospho-C-MET & 96 & 0.48617 & $<.0001$ \\
Phospho-IGFR & 56 & 0.49899 & $<.0001$ \\
Phospho-PI3K & 85 & 0.33682 & 0.0016 \\
Phospho-SHC & 92 & 0.51318 & $<.0001$ \\
Total HER1 & 95 & 0.50101 & $<.0001$ \\
Total HER2 & 99 & 0.46615 & $<.0001$ \\
Total HER3 & 94 & 0.46471 & $<.0001$ \\
Total C-MET & 96 & 0.56100 & $<.0001$ \\
Total IGFR & 55 & 0.38793 & 0.0034 \\
Phospho-AKT & 84 & 0.61217 & $<.0001$ \\
Phospho-ERK1/2 & 76 & 0.45454 & $<.0001$ \\
Phospho-MEK & 64 & 0.57802 & $<.0001$ \\
Phospho-RSK & 64 & 0.47930 & $<.0001$ \\
Phospho-PRAS40 & 72 & 0.51943 & $<.0001$ \\
Phospho-RPS6 & 71 & 0.32136 & 0.0063 \\
\hline
\end{tabular}

months, range 0.2 months $\sim 5$ years) as a cut-off (Table 4 ). When markers between these two survival groups were compared, we found that tumors associated with poor survival had a strong trend towards having higher total c-MET level compared to those with better survival ( $p=$ $0.05)$, resonating previous report showing c-MET to be frequently overexpressed and represents an independent poor prognostic factor in resected PDAC patients $[18,19]$. Interestingly, patients with poor survival had significantly lower levels of p-SHC $(p=0.002)$, p-PRAS40 $(\mathrm{p}=0.002)$ and $\mathrm{p}-\mathrm{AKT}(p=0.025)$. Partly resonating this finding, another study also showed that high p-AKT IHC staining in resected PDAC samples was associated with better patient prognosis [20].

Besides these biomarkers, clinical parameters such as clinical stage (including tumor size and lymph node status), tumor grade, age at diagnosis, medical comorbidities all have significant prognostic implication in PDAC patients. All these individual parameters culminate into a composite decision of surgical resection, which to date is the single most important prognostic factor in the outcome of PDAC patients [21]. Of all 70 PDAC patients we analyzed, patients who underwent curative resection $(\mathrm{N}=13$, or $18.6 \%)$ had a median survival of 20.8 months (range 5.1 months $\sim$ alive at 46 months) compared to 8.2 months (range 0.2 33 months, all died) for those who could not be resected $(\mathrm{N}=57$, or $81.4 \%$, Wilcoxon $\mathrm{p}=0.003$ ). Among these 70 patients, we did not detect statistically significant differences in survival based on age, tumor size, nodal status, stage, or tumor grade, probably due to small sample size and the fact that most patients were diagnosed at inoperable stages. Of the 57 non-operable patients, patients with locally-advanced ( $\mathrm{N}$ $=37)$ or metastatic disease $(\mathrm{N}=20)$ had a median OS of 9.7 and 6.7 months respectively, which did not reach statistical significance (Wilcoxon $\mathrm{P}=0.36$ ) probably due to small sample size and the inherent aggressive nature of this disease.

We next explored the prognostic impact of each marker among the inoperable patients $(\mathrm{N}=57)$, which is rarely reported in the literature due to the limited availability of PDAC tissues from these patients. By focusing on these patients, we believe we could more accurately capture the biological role of each marker in the natural progression of PDAC without the dramatic interference of surgical removal. Therefore, any markers later found to have prognostic impact could have a larger therapeutic implication in the future as most PDAC patients are either diagnosed at, or eventually will progress to, advanced stage. To this end, we divided all 57 patients into two groups using median OS (8.2 months) as a cut-off, and compared the intensity of all markers between these two groups (Table 4). Again, we found that patients will poorer prognosis had significantly higher expression levels of total c-MET $(p=0.027)$. Interestingly, these patients also had significantly higher levels of $p$-SHC and p-PRAS40 ( $p=0.006$ and $p=0.032$, respectively). Importantly, patients with poorer prognosis were significantly older (mean 72.4 years old) compared to those with better prognosis (mean 64.5 years old, $\mathrm{p}=$ 
Table 3: Comparison of overall marker intensities between negative vs PDAC specimens

\begin{tabular}{|l|l|l|l|}
\hline \multirow{2}{*}{ Covariate } & \multicolumn{2}{|c|}{ Signal Intensity, CU/ug (Mean \pm SD, median) } & \multirow{2}{*}{ P value } \\
\cline { 2 - 3 } & \multicolumn{1}{|c|}{ Negative (N=10) } & \multicolumn{1}{c|}{ PDAC (N=70) } & \\
\hline Total Cytokeratin (CK) & $116.76 \pm 167.12,47.15$ & $536.93 \pm 733.89,354.25$ & $\mathbf{0 . 0 0 2}$ \\
\hline Phospho-HER1 & $4.17 \pm 5.76,1.89$ & $1.95 \pm 2.65,1.03$ & 0.234 \\
\hline Phospho-HER2 & $0.33 \pm 0.35,0.14$ & $2.78 \pm 4.2,1.15$ & $\mathbf{0 . 0 0 7}$ \\
\hline Phospho-HER3 & $14.12 \pm 14.84,7.65$ & $38.36 \pm 45.71,22.98$ & $\mathbf{0 . 0 2 6}$ \\
\hline Phospho-C-MET & $0.15 \pm 0.16,0.05$ & $0.76 \pm 1.46,0.26$ & 0.051 \\
\hline Phospho-IGFR & $37.30 \pm 47.26,29.16$ & $25.61 \pm 45.06,12.06$ & 0.363 \\
\hline Phospho-PI3K & $46.37 \pm 44.40,25.17$ & $33.49 \pm 32.5,28.93$ & 0.399 \\
\hline Phospho-SHC & $3.23 \pm 4.14,1.84$ & $5.56 \pm 5.62,4.21$ & 0.200 \\
\hline Total HER1 & $54.38 \pm 47.42,42$ & $61.44 \pm 62.16,40.25$ & 0.765 \\
\hline Total HER2 & $1.22 \pm 1.26,0.55$ & $10.18 \pm 14.46,3.9$ & $\mathbf{0 . 0 0 6}$ \\
\hline Total HER3 & $54.72 \pm 66.72,25.0$ & $387.96 \pm 722.64,120.2$ & $\mathbf{0 . 0 0 8}$ \\
\hline Total c-MET & $72.65 \pm 66.73,60.0$ & $441.29 \pm 649.53,288.05$ & $<\mathbf{0 . 0 0 1}$ \\
\hline Total IGFR & $23.82 \pm 15.67,15.0$ & $83.69 \pm 108.82,43.34$ & $\mathbf{0 . 0 1 2}$ \\
\hline Phospho-AKT & $0.80 \pm 1.23,0.26$ & $3.25 \pm 5.47,1.36$ & $\mathbf{0 . 0 4 6}$ \\
\hline Phospho-ERK1/2 & $0.92 \pm 0.86,0.88$ & $7.8 \pm 10.66,4.78$ & $<\mathbf{0 . 0 0 1}$ \\
\hline Phospho-MEK & $0.36 \pm 0.21,0.43$ & $1.77 \pm 2.54,0.74$ & 0.120 \\
\hline Phospho-RSK & $24.06 \pm 17.89,14.94$ & $80.26 \pm 80.7,48.02$ & 0.127 \\
\hline Phospho-PRAS40 & $12.61 \pm 28.33,1.0$ & $41.6 \pm 68.5,9.24$ & $\mathbf{0 . 0 4 3}$ \\
\hline Phospho-RPS6 & $50.13 \pm 87.00,4.84$ & $18.74 \pm 60.08,1.58$ & 0.377 \\
\hline
\end{tabular}

0.018), consistent with published literature showing older age as a poor prognostic marker [22].

\section{Independent validation of prognostic significance of c-MET using PDAC tissue microarray}

While the robust quantitative capability of the CEER $^{\mathrm{TM}}$ platform has enabled prognostication to be ascribed to certain markers such as total c-Met, p-SHC and p-PRAS40, further validation is needed. First, high level of c-MET immunohistochemical staining in resected PDAC tumors has already been reported by different groups to be a poor prognostic marker $[18,19]$. Second, to further confirm this finding, we performed c-MET IHC staining on an independent PDAC tissue microarray built at our institution. Using the MetMab visual IHC scoring criteria $(0$ to $3+)$ that is widely adopted $[23,24]$ (Figure $2 \mathrm{~A}$ ), we found that the overall expression of c-MET is high (MetMab IHC score 2+ or 3+) in 53 out of 140 samples (or $37.9 \%$ ) of all PDAC samples. Consistent with our findings from the CEER ${ }^{\mathrm{TM}}$ platform, high c-MET IHC score is associated with poor prognosis in this independent cohort of patients $(p=0.03)$ (Figure 2B). On further analysis of PDAC samples, we indeed found significant correlation between the intensities of total and phospho-c-MET signals (Spearman $r$ 0.64, $p<0.0001$; Figure $2 \mathrm{C}$ ), further supporting targeting c-MET to improve the outcome for PDAC patients. Overall, our results further substantiate the quantifying power of the $\mathrm{CEER}^{\mathrm{TM}}$ platform, rendering it extremely useful in future clinical trial design.

\section{DISCUSSION}

Development of a powerful "functional" diagnostic is direly needed to monitor treatment response in the era of targeted therapy. The described CEER ${ }^{\mathrm{TM}}$ platform is particularly powerful in many aspects. First, this platform provides, in addition to expression levels, activation status of multiple key signaling molecules, which is impossible with current transcriptomic or genomic techniques. In PDAC, inhibitors that target the key KRas effectors such as the Raf-MEK-ERK and PI3K-AKT-mTOR pathways are being actively pursued in clinical trials, albeit with little success due to rapid emergence of various different resistance mechanisms including kinome reprogramming [26]. While these mechanisms can be readily identified, and overcome using cultured cells in the lab, being able to do so in the clinic in real time is essential in initial clinical trial allocation, and informing combinatorial strategies if no response is seen. To this end, the CEER ${ }^{\mathrm{TM}}$ technique could potentially provide a comprehensive, quantifiable signaling changes across multiple signaling pathways within the tumor tissues before and after 
Table 4: Prognostic significance of age and tested markers in PDAC patients

\begin{tabular}{|c|c|c|c|c|c|c|c|}
\hline Covariate & Statistics & & I patients ( & & & surgery (I & \\
\hline & & $\begin{array}{c}\text { Survival } \\
\leq \text { median }\end{array}$ & $\begin{array}{c}\text { Survival } \\
>\text { median }\end{array}$ & $\mathrm{P}$ value & $\begin{array}{c}\text { Survival } \\
\leq \text { median }\end{array}$ & $\begin{array}{c}\text { Survival } \\
>\text { median }\end{array}$ & $P$ value \\
\hline Age & $\begin{array}{c}\text { Mean } \\
\text { Median }\end{array}$ & $\begin{array}{l}70.9 \\
71.6\end{array}$ & $\begin{array}{l}65.1 \\
64.9\end{array}$ & 0.055 & $\begin{array}{l}72.4 \\
71.8\end{array}$ & $\begin{array}{l}64.5 \\
64.8\end{array}$ & 0.018 \\
\hline Phospho-HER1 & $\begin{array}{l}\text { Mean } \\
\text { Median }\end{array}$ & $\begin{array}{l}1.85 \\
0.77\end{array}$ & $\begin{array}{l}2.03 \\
1.44\end{array}$ & 0.291 & $\begin{array}{l}1.39 \\
0.63\end{array}$ & $\begin{array}{l}1.89 \\
1.48\end{array}$ & 0.235 \\
\hline Phospho-HER2 & $\begin{array}{c}\text { Mean } \\
\text { Median }\end{array}$ & $\begin{array}{l}3.07 \\
0.81\end{array}$ & $\begin{array}{l}2.49 \\
1.81\end{array}$ & 0.379 & $\begin{array}{l}2.66 \\
0.74\end{array}$ & $\begin{array}{l}2.37 \\
1.68\end{array}$ & 0.442 \\
\hline Phospho-HER3 & $\begin{array}{c}\text { Mean } \\
\text { Median }\end{array}$ & $\begin{array}{l}34.09 \\
20.97\end{array}$ & $\begin{array}{l}42.13 \\
29.91\end{array}$ & 0.459 & $\begin{array}{l}28.72 \\
22.29\end{array}$ & $\begin{array}{l}33.42 \\
25.21\end{array}$ & 0.806 \\
\hline Phospho-c-MET & $\begin{array}{c}\text { Mean } \\
\text { Median }\end{array}$ & $\begin{array}{l}0.99 \\
0.16\end{array}$ & $\begin{array}{l}0.55 \\
0.39\end{array}$ & 0.453 & $\begin{array}{c}0.7 \\
0.16\end{array}$ & $\begin{array}{l}0.61 \\
0.28\end{array}$ & 0.601 \\
\hline Phospho-IGFR & $\begin{array}{c}\text { Mean } \\
\text { Median }\end{array}$ & $\begin{array}{c}32.72 \\
11.7\end{array}$ & $\begin{array}{l}19.12 \\
12.06\end{array}$ & 0.702 & $\begin{array}{l}33.4 \\
11.7\end{array}$ & $\begin{array}{l}15.04 \\
10.64\end{array}$ & 0.462 \\
\hline Phospho-PI3K & $\begin{array}{c}\text { Mean } \\
\text { Median }\end{array}$ & $\begin{array}{l}28.79 \\
23.72\end{array}$ & $\begin{array}{l}37.79 \\
30.46\end{array}$ & 0.451 & $\begin{array}{l}27.05 \\
23.72\end{array}$ & $\begin{array}{c}30.4 \\
28.73\end{array}$ & 0.802 \\
\hline Phospho-SHC & $\begin{array}{l}\text { Mean } \\
\text { Median }\end{array}$ & $\begin{array}{l}3.83 \\
2.03\end{array}$ & $\begin{array}{l}7.15 \\
6.42\end{array}$ & 0.002 & $\begin{array}{l}3.03 \\
1.83\end{array}$ & $\begin{array}{l}6.66 \\
6.17\end{array}$ & 0.006 \\
\hline Total HER1 & $\begin{array}{l}\text { Mean } \\
\text { Median }\end{array}$ & $\begin{array}{l}64.88 \\
47.41\end{array}$ & $\begin{array}{l}58.19 \\
35.37\end{array}$ & 0.839 & $\begin{array}{l}61.05 \\
47.41\end{array}$ & $\begin{array}{l}46.29 \\
33.51\end{array}$ & 0.390 \\
\hline Total HER2 & $\begin{array}{c}\text { Mean } \\
\text { Median }\end{array}$ & $\begin{array}{l}9.78 \\
2.93\end{array}$ & $\begin{array}{c}10.55 \\
5.8\end{array}$ & 0.309 & $\begin{array}{l}8.72 \\
2.55\end{array}$ & $\begin{array}{l}8.88 \\
4.42\end{array}$ & 0.396 \\
\hline Total HER3 & $\begin{array}{c}\text { Mean } \\
\text { Median }\end{array}$ & $\begin{array}{c}455.48 \\
106.7\end{array}$ & $\begin{array}{c}326.22 \\
129.2\end{array}$ & 0.779 & $\begin{array}{l}433.26 \\
113.05\end{array}$ & $\begin{array}{l}240.94 \\
102.35\end{array}$ & 0.728 \\
\hline Total c-MET & $\begin{array}{c}\text { Mean } \\
\text { Median }\end{array}$ & $\begin{array}{c}619.84 \\
385.7\end{array}$ & $\begin{array}{c}272.95 \\
213.5\end{array}$ & 0.050 & $\begin{array}{l}684.9 \\
440.3\end{array}$ & $\begin{array}{c}260.19 \\
154.4\end{array}$ & 0.027 \\
\hline Total IGFR & $\begin{array}{c}\text { Mean } \\
\text { Median }\end{array}$ & $\begin{array}{c}92.94 \\
41.5\end{array}$ & $\begin{array}{l}74.97 \\
45.17\end{array}$ & 0.807 & $\begin{array}{c}86.39 \\
41.5\end{array}$ & $\begin{array}{l}57.72 \\
39.53\end{array}$ & 0.396 \\
\hline Phospho-AKT & $\begin{array}{c}\text { Mean } \\
\text { Median }\end{array}$ & $\begin{array}{l}1.76 \\
0.82\end{array}$ & $\begin{array}{l}4.57 \\
3.19\end{array}$ & 0.025 & $\begin{array}{l}1.72 \\
0.78\end{array}$ & $\begin{array}{l}3.55 \\
2.94\end{array}$ & 0.062 \\
\hline Phospho-ERK1/2 & $\begin{array}{c}\text { Mean } \\
\text { Median }\end{array}$ & $\begin{array}{l}7.62 \\
4.31\end{array}$ & $\begin{array}{l}7.96 \\
6.22\end{array}$ & 0.482 & $\begin{array}{l}8.04 \\
4.39\end{array}$ & $\begin{array}{l}6.65 \\
6.22\end{array}$ & 0.665 \\
\hline Phospho-MEK & $\begin{array}{c}\text { Mean } \\
\text { Median }\end{array}$ & $\begin{array}{l}1.36 \\
0.53\end{array}$ & $\begin{array}{c}2.12 \\
1.1\end{array}$ & 0.318 & $\begin{array}{l}1.24 \\
0.54\end{array}$ & $\begin{array}{l}1.68 \\
1.01\end{array}$ & 0.701 \\
\hline Phospho-RSK & $\begin{array}{c}\text { Mean } \\
\text { Median }\end{array}$ & $\begin{array}{l}84.14 \\
44.07\end{array}$ & $\begin{array}{l}76.79 \\
73.75\end{array}$ & 0.572 & $\begin{array}{l}88.02 \\
34.24\end{array}$ & $\begin{array}{l}73.11 \\
46.58\end{array}$ & 0.716 \\
\hline Phospho-PRAS40 & $\begin{array}{l}\text { Mean } \\
\text { Median }\end{array}$ & $\begin{array}{c}22.03 \\
2.94\end{array}$ & $\begin{array}{c}59.5 \\
31.26\end{array}$ & 0.002 & $\begin{array}{c}21.12 \\
3.16\end{array}$ & $\begin{array}{l}42.87 \\
13.73\end{array}$ & 0.032 \\
\hline Phospho-RPS6 & $\begin{array}{c}\text { Mean } \\
\text { Median }\end{array}$ & $\begin{array}{c}20.31 \\
1.26\end{array}$ & $\begin{array}{c}17.35 \\
1.58\end{array}$ & 0.475 & $\begin{array}{c}24.28 \\
1.26\end{array}$ & $\begin{array}{c}16.64 \\
1.52\end{array}$ & 0.911 \\
\hline
\end{tabular}


therapeutic intervention. Second, the ultra-sensitivity of this platform allows analysis to be performed using scant amount of tissues such as FNA samples, which is especially attractive for clinical trials on pancreatic cancer, where tissues are limited and prone to degradation by catalytic enzymes in the pancreas. Third, the CEER ${ }^{\mathrm{TM}}$ platform provides clear proteomic distinction between normal pancreatic and PDAC tissues, indicating robust specificity. For instance, significantly higher signal intensity of EGFR/HER signaling, total c-MET, total IGFR, p-AKT, p-ERK1/2 and p-PRAS40 were seen in PDAC compared to non-cancerous samples. Of these markers, enhanced phosphorylation of ERK1/2, AKT and PRAS40 are all known events driven by the KRas oncoprotein. Therefore, these markers could serve as readouts in clinical trials for various inhibitors against the KRas effectors. Forth, processing of tumor specimens and data analysis are relatively less sophisticated than genomic or transcriptomic tools, which will diminish both cost and turnaround time. In summary, all these advantageous features render the $\mathrm{CEER}^{\mathrm{TM}}$ technique an extremely attractive companion diagnostic in future clinical trial design.
An important finding from analyzing the result from $\mathrm{CEER}^{\mathrm{TM}}$ is the wide patient-to-patient variability in the signal intensity of each marker. This finding is reflective of the highly heterogeneous biology of PDAC, as supported by discovery of various molecular subtypes of PDAC based on genomic and transcriptomic analyses [2-4]. On this basis, the CEER ${ }^{\mathrm{TM}}$ platform may be able to provide essential complementary proteomic data that could aid treatment selection and even prognostication. Supporting this notion, we showed that high level of c-MET expression by CEER ${ }^{\mathrm{TM}}$ is associated with inferior survival for patients with advanced inoperable PDAC. We validated this data by immunohistochemistry, which is the most widely accepted technique. In addition, the poor prognostication of high c-MET level in PDAC has also been published in retrospective analysis [19], and preclinical studies also show that activation of c-MET in PDAC can enhance proliferation, survival, invasiveness, and treatment resistance $[14,25]$. Several c-MET inhibitors are being evaluated in clinical trials for various cancer types including PDAC, with promising results still lacking, presumably due to poor patient selection and de novo resistance [27]. Biomarkers to predict response such

Total C-MET IHC (TMA)

A

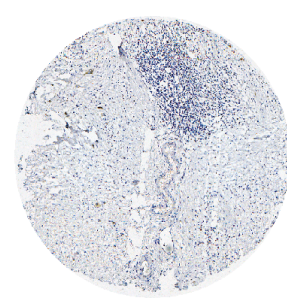

0

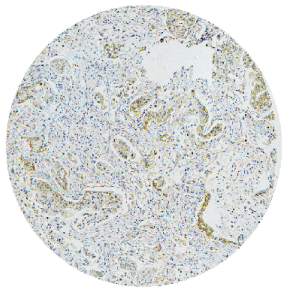

1

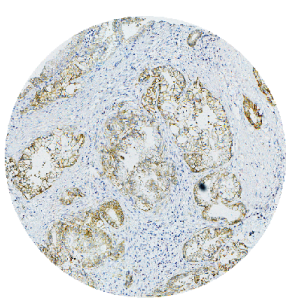

2

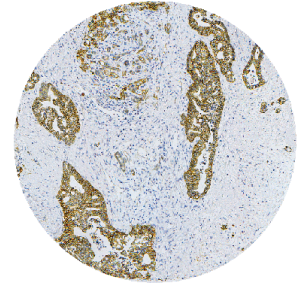

3
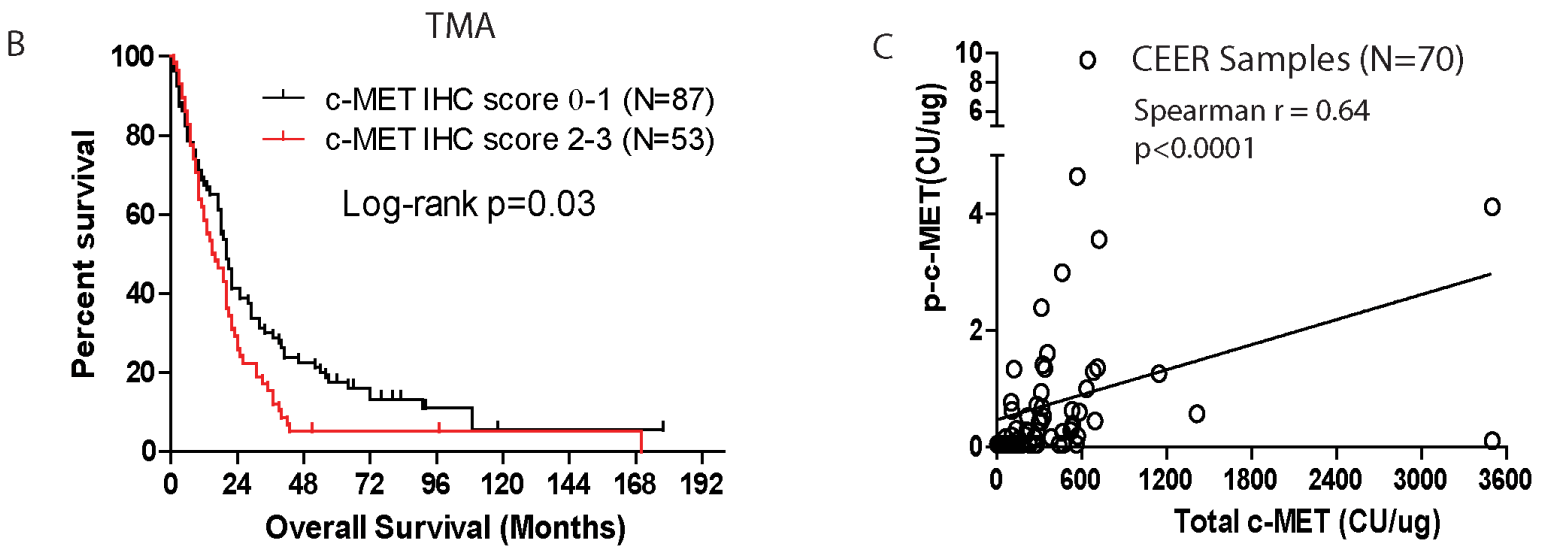

Figure 2: Independent validation of prognostic significance of total c-MET IHC staining in PDAC tissue microarray from another cohort of $\mathbf{1 4 0}$ patients. A. Representative IHC images showing various assigned intensity of total c-MET staining in PDAC tissue microarray. B. Kaplan-Meier survival analysis of patients based on c-MET IHC score. C. Spearman correlation between total and phospho-c-MET signals of FNA samples subject to CEERTM. 
as circulating HGF or c-MET levels, c-MET genomic amplification or protein overexpression are being assessed. To this end, the CEER ${ }^{\mathrm{TM}}$ technique could certainly provide pre-treatment levels of total and activated c-MET to aid patient selection, and importantly, assessment of ontarget effect and potential escape mechanisms at treatment failure.

Intriguingly, our data showed that high phosphorylation of SHC and PRAS40 proteins to be associated with better prognosis in PDAC patients, which have not been reported. In contrast, high p-SHC correlates with aggressive features and poor prognosis in gastric and breast cancer [28, 29], which underscores caution when extrapolating research data from one cancer type to another. The SHC proteins consists of three different splicing isoforms, p46shc, p52shc and p66shc, and are all members of the Src homologous- collagen homologue adaptor protein family that have very divergent roles in regulating signal downstream of growth factor receptors [30]. Since the antibody used in our CEER ${ }^{\mathrm{TM}}$ platform recognizes all three SHC isoforms, development of isoform-specific phospho-SHC antibodies will be invaluable in informing the prognostic implication of each isoform and provide novel therapeutic opportunities. Similarly, the association of higher p-PRAS40 with better survival in PDAC is also different from a study in gastric cancer, where presence of p-PRAS40 was associated with aggressive histologic features and poor prognosis [28]. The proline-rich AKT substrate of 40-kDA (PRAS40) is a substrate of AKT which functions as an inhibitor to mTORC1 complex in regulating glucose metabolism $[31,32]$. To date, the role of PRAS40 in PDAC is largely unclear and should be investigated. Overall, these interesting observations underscore the ability of the $\mathrm{CEER}^{\mathrm{TM}}$ in revealing, in an unbiased manner, novel and potentially important clues that can be pursued.

There are a few limitations in our study. First, low tumor cellularity and tumor heterogeneity remain concerns especially in PDAC. Although we focused our analyses on the FNA sample that has the higher CK value, signals from stromal and immune cells may interfere with the readouts we obtained. In future studies, more FNA passes should be obtained for analysis of the sample with the highest $\mathrm{CK}$ value. Second, we are unable to determine the prognostic impact of different chemotherapeutic regimens on patient survival due to small patient number $(\mathrm{N}=57)$. However, all patients received systemic treatment per the NCCN guidelines, which include 5-FU or gemcitabinebased chemotherapy regimens as standard-of-care or part of clinical trials. Larger studies in the future are needed to confirmed the prognostic impact of individual markers examined in our present study.

In conclusion, we demonstrate, for the first time in literature successful utilization of an unbiased, proteomicbased functional diagnostic that allows comprehensive elucidation and quantification of signaling aberrations in primary PDAC tumors. We demonstrate that this technique is clinically feasible, highly sensitive, specific and reliable. In the current era of precision oncology when the use of kinase inhibitor is increasingly frequent, this technique could provide irreplaceable proteomic information within the tumor, which could be critical in assessing the treatment effect and providing secondary signaling changes that could inform resistance mechanisms. As such, we believe this technique has irreplaceable value, in complement to genomic and transcriptomic tools, in realizing the goals of personalized oncology.

\section{MATERIALS AND METHODS}

\section{Tumor specimen procurement}

Tumor specimens were prospectively collected via endoscopic ultrasound-guided fine needle aspiration (EUSFNA) from 102 patients presenting with a suspicious pancreatic mass as summarized in Figure 1A. Informed consent, specimen collection and future data collection were all conducted under IRB approval (Washington University in St. Louis IRB protocol \#201106347). In addition to the passes obtained for routine clinical care, two EUS-FNA passes were performed and immediately collected in separate vials containing $100 \mu \mathrm{l}$ of preservation and lysis solution (proprietary information, Prometheus Laboratories Inc.). The resulting lysates were shipped to Prometheus Laboratories (San Diego, CA) at ambient temperature within 48 hours of sample collection, and stored at $-70^{\circ} \mathrm{C}$ upon receipt until subsequent $\mathrm{CEER}{ }^{\mathrm{TM}}$ analysis.

\section{Collaborative enzyme enhanced reactive immunoassay $\left(\mathrm{CEER}^{\mathrm{TM}}\right)$}

To measure the expression and activation levels of receptor tyrosine kinases and signal transduction proteins in clinical specimens, we employed CEER ${ }^{\mathrm{TM}}$, a highly sensitive multiplexed immunoarray platform. Detailed methods for this technology have been described previously [1-5]. Briefly, capture antibodies (Abs) were printed on nitrocellulose-coated glass slides $\left(\right.$ ONCYTE $^{\mathrm{R}}$ Grace Biolabs) using a non-contact printer (Nano-Plotter, GeSiM). The spot diameter was approximately $175 \mu \mathrm{m}$ and printed slides were kept in a desiccated chamber at room temperature. Capture Abs were printed in triplicate and at serial dilution concentrations of $1 \mathrm{mg} / \mathrm{mL}$ and 0.5 $\mathrm{mg} / \mathrm{mL}$. Purified mouse-IgGs served as negative controls. Immunoarray slide configurations and assay format were performed as previously described [1-5]. Briefly, immunoarray slides were rinsed with TBST $(50 \mathrm{mM}$ Tris/ $150 \mathrm{mM} \mathrm{NaCl} / 0.1 \%$ Tween-20, $\mathrm{pH}$ 7.2-7.4) and blocked for 1 hour at room temperature (RT). Serially 
diluted lysate controls in $80 \mu \mathrm{L}$ dilution buffer $(2 \% \mathrm{BSA} /$ $0.1 \%$ TritonX-100/ TBS, $\mathrm{pH} 7.2-7.4$ ) and samples were added to designated sub-arrays on slides, then incubated overnight at RT. After several washes, slides were incubated with two detector Abs (for different epitopes) conjugated with glucose oxidase (GO) and horseradish peroxidase (HRP) respectively for 2 hours at RT. After washing slides with TBST to remove unbound detector Abs, GO/HRP-mediated tyramide signal amplification process was triggered by adding biotin-tyramide solution and incubating for 30 mins. Local deposition of biotintyramide was detected by incubation with streptavidinAlexa Fluor647 (Life Technologies, Carlsbad, CA) for $40 \mathrm{~min}$. Slides were washed with TBST, dried and immediately processed on a high-resolution fluorescence microarray scanner (PowerScanner, Tecan). Backgroundcorrected signal intensities were averaged for capture antibodies printed in triplicate. For each marker, a standard curve was generated from serially diluted control lysates prepared from specific cell lines. HCC827, a NSCLC adenocarcinoma cell line carrying EGFR gene amplification and exon 19 deletion, was used for EGFR and MET quantifications, while breast cancer cell lines BT474 and T47D, served for HER2/PRAS40/RPS6 and HER3/IGF1R/PI3K/CK quantifications respectively. Alternatively, standard curves were generated from serially diluted recombinant proteins for AKT, ERK, MEK and RSK assays. Each curve was plotted as a function of signal intensity measured as relative fluorescence unit (RFU) vs. log concentration of cell lysates/ recombinant proteins or Computed Unit (CU). The data were fit to a five-parameter equation by nonlinear regression, simultaneously fitting both dilutions of the capture $\mathrm{Ab}$ as described previously $[10,33]$. CEER measurements are determined in Computed Unit (CU). CU is a representation of marker expression/ activation in unknown samples relative to that of control cell lines with known expression /activation levels. Hence, a sample with $1 \mathrm{CU}$ of HER1 expression has an RFU value equivalent to 1 standard reference $\mathrm{HCC} 827$ cell. Because expression and activation of each marker is determined in unique CEER ${ }^{\mathrm{TM}}$ assays with different cell line standards, only CU values of the same marker across various samples can be compared.

\section{Pancreatic cancer TMA, c-Met immunohistochemistry (IHC) and scoring}

The PDAC TMA was constructed from FFPE surgical specimens archived at the Department of Pathology and Immunology at Washington University under IRB approval and was previously published [34, 35]. Complete treatment history, clinical follow up and outcomes were available for all patients. For total c-MET staining, antigen-retrieval was performed by incubation in $0.01 \mathrm{~mol} / \mathrm{L}$ citrate buffer $(\mathrm{pH} 6.0)$ and heating in a pressure cooker. Sections were incubated at $4^{\circ} \mathrm{C}$ overnight with total c-MET antibody (D1C2, Cell Signaling Technology, 1:200), followed by staining using the DAB Peroxidase (HRP) Substrate Kit with Nickel (Vector Laboratories cat\#SK-4100). Stained slides were digitalized and scored independently by a GI pathologist (D.C) in blinded fashion using the MetMab IHC scoring method as published [23, 24]. Briefly, stained tumors were scored between 0-3+ based on : 0 : no staining or $<50 \%$ of tumor cells with any intensity; $1+: \geq 50 \%$ of tumor cells with weak or higher intensity but $<50 \%$ with moderate or higher intensity; $2+$ : $\geq 50 \%$ of tumor cells with moderate or higher intensity but $<50 \%$ with strong intensity; $3+: \geq 50 \%$ of tumor cells staining with strong intensity).

\section{Statistical analysis}

Due to the presence of detecting limits, all the measured markers were analyzed using non-parametric tests which were based on relative ranks rather than absolute values. The correlation between two FNA passes from the same patients were assessed using Spearman correlation coefficient. In subsequent analysis, the FNA pass with higher cytokeratin (CK) level was retained for data analysis. The difference in each marker between positive and negative PDAC samples was compared using Mann-Whitney rank-sum test. Among these 70 patients with positive PDAC, only 2 patients (who happened to have the longest follow-up times) were censored and the survival times were observed in all other patients. To assess the prognostic value of each marker on survival, the patients were categorized into 2 groups by median survival time, and the between-group difference in each marker was then compared using Mann-Whitney rank-sum test. The survival curves by other clinical characteristics such as stage and grade were also estimated using Kaplan-Meier product limit method. Since almost all the patients died during follow-up and the estimated survival curves were more likely to converge eventually, the difference between survival curves were compared by Gehan-Breslow-Wilcoxon (Wilcoxon) method (which is less sensitive to the proportional hazard assumption). All the tests were two-sided with p-value of 0.05 indicating significance. The data was analyzed using the standard package of SAS (Version 9.3, SAS Institute, Cary, NC).

\section{ACKNOWLEDGMENTS}

Authors would like to acknowledge Dr. Limin Liu for his help in processing clinical samples upon receipt at Prometheus Laboratories.

\section{CONFLICTS OF INTEREST}

The authors declared no conflict of interests. 


\section{FUNDING}

The study received support from the Foundation for Barnes-Jewish Hospital Cancer Frontier Fund Program. The Siteman Cancer Center Biostatistics Shared Resource (BSR) is supported by NCI Cancer Center Support Grant \#P30 CA091842 (PI: Dr. Timothy Eberlein).

\section{Author contributions}

AWG and RA designed the study; AWG, RA, VMK, DSE, DKM, SAE, SW, FM recruited patients and collected specimens; EM, PK, GM and SS processed the specimens, performed CEER assay and quantification; AWG and KHL collected clinical data; AWG, KHL, FG and JL analyzed, interpreted all data and wrote the manuscript; LL performed IHC of tumor microarray and assisted with scoring; DC performed independent scoring of c-MET IHC.

\section{Editorial note}

This paper has been accepted based in part on peerreview conducted by another journal and the authors' response and revisions as well as expedited peer-review in Oncotarget.

\section{REFERENCES}

1. Ryan DP, Hong TS, Bardeesy N. Pancreatic adenocarcinoma. N Engl J Med. 2014; 371: 2140-1. doi: 10.1056/NEJMc1412266.

2. Bailey P, Chang DK, Nones K, Johns AL, Patch AM, Gingras MC, Miller DK, Christ AN, Bruxner TJ, Quinn MC, Nourse C, Murtaugh LC, Harliwong I, et al. Genomic analyses identify molecular subtypes of pancreatic cancer. Nature. 2016; 531: 47-52. doi: 10.1038/nature16965.

3. Waddell N, Pajic M, Patch AM, Chang DK, Kassahn KS, Bailey P, Johns AL, Miller D, Nones K, Quek K, Quinn MC, Robertson AJ, Fadlullah MZ, et al. Whole genomes redefine the mutational landscape of pancreatic cancer. Nature. 2015; 518: 495-501. doi: 10.1038/nature14169.

4. Biankin AV, Waddell N, Kassahn KS, Gingras MC, Muthuswamy LB, Johns AL, Miller DK, Wilson PJ, Patch AM, Wu J, Chang DK, Cowley MJ, Gardiner BB, et al. Pancreatic cancer genomes reveal aberrations in axon guidance pathway genes. Nature. 2012; 491: 399-405. doi: 10.1038/nature11547.

5. Bardeesy N, DePinho RA. Pancreatic cancer biology and genetics. Nat Rev Cancer. 2002; 2: 897-909.

6. Teague A, Lim KH, Wang-Gillam A. Advanced pancreatic adenocarcinoma: a review of current treatment strategies and developing therapies. Ther Adv Med Oncol. 2015; 7: 68-84. doi: 10.1177/1758834014564775.
7. Knudsen ES, O’Reilly EM, Brody JR, Witkiewicz AK. Genetic Diversity of Pancreatic Ductal Adenocarcinoma and Opportunities for Precision Medicine. Gastroenterology. 2016; 150: 48-63. doi: 10.1053/j.gastro.2015.08.056.

8. Friedman AA, Letai A, Fisher DE, Flaherty KT. Precision medicine for cancer with next-generation functional diagnostics. Nat Rev Cancer. 2015; 15: 747-56. doi: 10.1038/nrc4015.

9. Garrido-Laguna I, Hidalgo M. Pancreatic cancer: from state-of-the-art treatments to promising novel therapies. Nat Rev Clin Oncol. 2015; 12: 319-34. doi: 10.1038/ nrclinonc.2015.53.

10. Kim P, Liu X, Lee T, Liu L, Barham R, Kirkland R, Leesman G, Kuller A, Ybarrondo B, Ng SC, Singh S. Highly sensitive proximity mediated immunoassay reveals HER2 status conversion in the circulating tumor cells of metastatic breast cancer patients. Proteome Sci. 2011; 9: 75. doi: 10.1186/1477-5956-9-75.

11. Sjoquist KM, Chin VT, Chantrill LA, O'Connor C, Hemmings C, Chang DK, Chou A, Pajic M, Johns AL, Nagrial AM, Biankin AV, Yip D. Personalising pancreas cancer treatment: When tissue is the issue. World $\mathrm{J}$ Gastroenterol. 2014; 20: 7849-63. doi: 10.3748/wjg.v20. i24.7849.

12. Moll R, Franke WW, Schiller DL, Geiger B, Krepler R. The catalog of human cytokeratins: patterns of expression in normal epithelia, tumors and cultured cells. Cell. 1982; 31: 11-24.

13. Furukawa T, Duguid WP, Kobari M, Matsuno S, Tsao MS. Hepatocyte growth factor and Met receptor expression in human pancreatic carcinogenesis. Am J Pathol. 1995; 147: 889-95.

14. Ebert M, Yokoyama M, Friess H, Buchler MW, Korc M. Coexpression of the c-met proto-oncogene and hepatocyte growth factor in human pancreatic cancer. Cancer Res. 1994; 54: 5775-8.

15. Qin R, Smyrk TC, Reed NR, Schmidt RL, Schnelldorfer T, Chari ST, Petersen GM, Tang AH. Combining clinicopathological predictors and molecular biomarkers in the oncogenic K-RAS/Ki67/HIF-1alpha pathway to predict survival in resectable pancreatic cancer. Br J Cancer. 2015; 112: 514-22. doi: 10.1038/bjc.2014.659.

16. Roberts PJ, Der CJ. Targeting the Raf-MEK-ERK mitogen-activated protein kinase cascade for the treatment of cancer. Oncogene. 2007; 26: 3291-310. doi: 10.1038/ sj.onc. 1210422 .

17. Ryan MB, Der CJ, Wang-Gillam A, Cox AD. Targeting -mutant cancers: is ERK the key? Trends Cancer. 2015; 1: 183-98. doi: 10.1016/j.trecan.2015.10.001.

18. Neuzillet C, Couvelard A, Tijeras-Raballand A, de Mestier L, de Gramont A, Bedossa P, Paradis V, Sauvanet A, Bachet JB, Ruszniewski P, Raymond E, Hammel P, Cros J. High c-Met expression in stage I-II pancreatic adenocarcinoma: proposal for an immunostaining scoring method and 
correlation with poor prognosis. Histopathology. 2015; 67: 664-76. doi: 10.1111/his.12691.

19. Zhu GH, Huang C, Qiu ZJ, Liu J, Zhang ZH, Zhao N, Feng ZZ, Lv XH. Expression and prognostic significance of CD151, c-Met, and integrin alpha3/alpha6 in pancreatic ductal adenocarcinoma. Dig Dis Sci. 2011; 56: 1090-8. doi: 10.1007/s10620-010-1416-x.

20. Chadha KS, Khoury T, Yu J, Black JD, Gibbs JF, Kuvshinoff BW, Tan D, Brattain MG, Javle MM. Activated Akt and Erk expression and survival after surgery in pancreatic carcinoma. Ann Surg Oncol. 2006; 13: 933-9. doi: 10.1245/ASO.2006.07.011.

21. Eloubeidi MA, Desmond RA, Wilcox CM, Wilson RJ, Manchikalapati P, Fouad MM, Eltoum I, Vickers SM. Prognostic factors for survival in pancreatic cancer: a population-based study. Am J Surg. 2006; 192: 322-9. doi: 10.1016/j.amjsurg.2006.02.017.

22. Amin S, Lucas AL, Frucht H. Evidence for treatment and survival disparities by age in pancreatic adenocarcinoma: a population-based analysis. Pancreas. 2013; 42: 249-53. doi: 10.1097/MPA.0b013e31825f3af4.

23. Spigel DR, Ervin TJ, Ramlau RA, Daniel DB, Goldschmidt JH, Jr., Blumenschein GR, Jr., Krzakowski MJ, Robinet G, Godbert B, Barlesi F, Govindan R, Patel T, Orlov SV, et al. Randomized phase II trial of Onartuzumab in combination with erlotinib in patients with advanced non-small-cell lung cancer. J Clin Oncol. 2013; 31: 4105-14. doi: 10.1200/ JCO.2012.47.4189.

24. Dziadziuszko R, Wynes MW, Singh S, Asuncion BR, Ranger-Moore J, Konopa K, Rzyman W, Szostakiewicz B, Jassem J, Hirsch FR. Correlation between MET gene copy number by silver in situ hybridization and protein expression by immunohistochemistry in non-small cell lung cancer. J Thorac Oncol. 2012; 7: 340-7. doi: 10.1097/ JTO.0b013e318240ca0d.

25. Di Renzo MF, Poulsom R, Olivero M, Comoglio PM, Lemoine NR. Expression of the Met/hepatocyte growth factor receptor in human pancreatic cancer. Cancer Res. 1995; 55: 1129-38.

26. Cox AD, Fesik SW, Kimmelman AC, Luo J, Der CJ. Drugging the undruggable RAS: Mission possible? Nat Rev Drug Discov. 2014; 13: 828-51. doi: 10.1038/nrd4389.

27. Garajova I, Giovannetti E, Biasco G, Peters GJ. c-Met as a Target for Personalized Therapy. Transl Oncogenomics. 2015; 7: 13-31. doi: 10.4137/TOG.S30534.
28. Lu YZ, Deng AM, Li LH, Liu GY, Wu GY. Prognostic role of phospho-PRAS40 (Thr246) expression in gastric cancer. Arch Med Sci. 2014; 10: 149-53. doi: 10.5114/ aoms.2013.36927.

29. Davol PA, Bagdasaryan R, Elfenbein GJ, Maizel AL, Frackelton AR, Jr. Shc proteins are strong, independent prognostic markers for both node-negative and nodepositive primary breast cancer. Cancer Res. 2003; 63: 677283.

30. Bhat SS, Anand D, Khanday FA. p66Shc as a switch in bringing about contrasting responses in cell growth: implications on cell proliferation and apoptosis. Mol Cancer. 2015; 14: 76. doi: 10.1186/s12943-015-0354-9.

31. Sancak Y, Thoreen CC, Peterson TR, Lindquist RA, Kang SA, Spooner E, Carr SA, Sabatini DM. PRAS40 is an insulin-regulated inhibitor of the $\mathrm{mTORC} 1$ protein kinase. Mol Cell. 2007; 25: 903-15. doi: 10.1016/j. molcel.2007.03.003.

32. Vander Haar E, Lee SI, Bandhakavi S, Griffin TJ, Kim $\mathrm{DH}$. Insulin signalling to mTOR mediated by the Akt/PKB substrate PRAS40. Nat Cell Biol. 2007; 9: 316-23. doi: $10.1038 /$ ncb1547.

33. Ward TM, Iorns E, Liu X, Hoe N, Kim P, Singh S, Dean S, Jegg AM, Gallas M, Rodriguez C, Lippman M, Landgraf R, Pegram MD. Truncated p110 ERBB2 induces mammary epithelial cell migration, invasion and orthotopic xenograft formation, and is associated with loss of phosphorylated STAT5. Oncogene. 2013; 32: 2463-74. doi: 10.1038/ onc.2012.256.

34. Jiang H, Hegde S, Knolhoff BL, Zhu Y, Herndon JM, Meyer MA, Nywening TM, Hawkins WG, Shapiro IM, Weaver DT, Pachter JA, Wang-Gillam A, DeNardo DG. Targeting focal adhesion kinase renders pancreatic cancers responsive to checkpoint immunotherapy. Nat Med. 2016; 22: 851-60. doi: 10.1038/nm.4123.

35. Sanford DE, Belt BA, Panni RZ, Mayer A, Deshpande AD, Carpenter D, Mitchem JB, Plambeck-Suess SM, Worley LA, Goetz BD, Wang-Gillam A, Eberlein TJ, Denardo $\mathrm{DG}$, et al. Inflammatory monocyte mobilization decreases patient survival in pancreatic cancer: a role for targeting the CCL2/CCR2 axis. Clin Cancer Res. 2013; 19: 3404-15. doi: 10.1158/1078-0432.CCR-13-0525. 